The Cryosphere Discuss., https://doi.org/10.5194/tc-2018-268

Manuscript under review for journal The Cryosphere

Discussion started: 4 January 2019

(C) Author(s) 2019. CC BY 4.0 License.

\title{
Shear failure of weak snow layers in the first hours after burial
}

\section{Benjamin Reuter ${ }^{1,2}$, Neige Calonne ${ }^{2,3}$ and Ed Adams ${ }^{2}$}

${ }^{1}$ WSL Institute for Snow and Avalanche Research SLF, Davos, Switzerland.

${ }^{2}$ Montana State University, Department of Civil Engineering, 205 Cobleigh Hall, Bozeman, MT 59717, U.S.A.

${ }^{3}$ Météo-France - CNRS, CNRM-GAME, UMR3589, CEN, 1441 rue de la piscine, 38400 Saint Martin d'Hères, France

Correspondance to: Benjamin Reuter (reuter@slf.ch)

Abstract. In a dry stratified snowcover slab avalanches release following failure in a weak layer below the slab. Typically, such weak layers consist either of persistent grain types or precipitation particles. Experience suggests that non-persistent instabilities often crest during or towards the end of a storm - probably because weak layers of precipitation particles strengthen rapidly. Studies so far have mainly focused on persistent grain types providing only sparse data to describe nonpersistent weak layer failure.

To understand differences between persistent and non-persistent weak layers we measured fracture mechanical properties relevant for avalanche release in a temporal series of laboratory tests. At defined lag times we tested small layered samples containing a weak layer of surface hoar, facets or decomposing fragmented particles in shear. Highspeed frames from the failure zone and image correlation analysis confirm that weak layers concentrate the shear strain. Failure consistently occurred after $20-30 \%$ of strain energy was dissipated - despite shear strain rates as high $10^{-2} \mathrm{~s}^{-1}$.

Our results of shear modulus and shear fracture toughness compare well with published data. The values for surface hoar and decomposing fragmented particles increased due to sintering. In the first hours after burial both weak layers had similarly low values, indicating they are equally fragile. Only for surface hoar and decomposing fragmented particles could we calibrate a formulation which allows for estimating the shear modulus from SMP signals.

Key words: snow fracture, snow failure, weak layer, image correlation, strain softening

\section{Introduction}

A snow slab avalanche releases when failure in a weak layer initiates underneath a cohesive slab. If the initial crack spreads across the slope the snow slab detaches and can move downhill (Schweizer et al., 2016). Weak layers are typically grouped into persistent and non-persistent grain types. Persistent grain types include slow metamorphosing faceted crystal types; surface hoar and depth hoar, whereas non-persistent grain types refer to precipitation particles and decomposing, fragmented particles which will readily develop into microstructure often less prone to fail. Proportions of persistent and non-persistent grain types vary with climate (Mock and Birkeland, 2000). Still, among human triggered avalanches, persistent weak layers are the most common (Schweizer and Lütschg, 2001), but in some snow climates proportions may change towards non-persistent grain types (Bair et al., 2012).

35 To date, field research on weak layer mechanical properties has mostly focused on persistent grain types. This is likely due to the fact that persistent weak layers are, as the name suggests, amenable to longer term field measurements, whereas nonpersistent instabilities only offer a short time window for field studies. In general, non-persistent weak layers cover a similar range of shear strength values as persistent weak layers, but are on average by about a third stronger (Jamieson and Johnston, 2001). Similarly, weak layers of non-persistent grain types span the full range of weak layer fracture energies,

40 with decomposing fragmented particles at the upper end and precipitation particles at the lower end (van Herwijnen et al., 2016).

Laboratory experiments with samples containing a weak layer were, at first, rare (Fukuzawa and Narita, 1993), because strain measurements had to be calculated based on displacement measurements of the entire sample, which are 
The Cryosphere Discuss., https://doi.org/10.5194/tc-2018-268

Manuscript under review for journal The Cryosphere

Discussion started: 4 January 2019

(c) Author(s) 2019. CC BY 4.0 License.

representative only of the uniform strain in homogeneous samples. Layered samples, however, develop strain concentrations in the weaker zones (Reiweger et al., 2010) requiring methods, such as imaging techniques, to study local strain (Walters et al., 2010). With particle imaging velocimetry layered samples have been analysed focusing on persistent weak layers. Samples containing a layer of surface hoar, facets or depth hoar were reported to fail in a brittle manner if loading rates were sufficiently high (Reiweger and Schweizer, 2013, 2010). Likewise, Walters and Adams (2014) observed brittle failure in radiation recrystallized faceted weak layers and measured strain concentrations with an image correlation technique. Moreover, they could link their measurements of modulus and strength to the anisotropic microstructure of the weak layers, highlighting temporal changes of fracture mechanical properties during snow metamorphism.

Although fracture mechanical properties of non-persistent grains can be as low as for persistent grain types, we are missing details on the failure behavior of these grain types. Field experience suggests that non persistent weak layers are active only during a short period, but little is known about temporal changes of their fracture mechanical properties and how they relate to isothermal metamorphism and sintering (Kaempfer and Schneebeli, 2007) - the most common process after burial.

As the temporal and spatial scales of release processes are beyond the resolution of space or airborne remote sensing techniques, the snow mechanical properties relevant for slab avalanche release need to be assessed by, ideally, a combined approach of ground measurements and modelling. In view of modelling artificial triggering, i.e. when the load is applied during short time scales $(<1 \mathrm{~s})$, failure initiation and crack propagation have been established as relevant processes of avalanche release (Haegeli and Schweizer, 2015). Both processes were shown to be relevant for snow instability (Gaume and Reuter, 2017) and modeled from field measurements of the vertical layering (Reuter and Schweizer, 2018). New advances, in particular to model the dynamics rather than only the onset of crack propagation, require a description of the material behavior in the failure zone. Data are thus required to describe the mismatch between the weak layer and the slab (Gaume et al., 2017) or the softening behavior prior to failure (Gaume et al., 2018). During natural release, deformation in the snowpack takes place at longer times scales (>1 s), and Capelli et al. (2018a) showed that healing of broken bonds or viscoelastic load redistribution are important processes for failure at lower rates. Hence, to model natural release, knowledge of the sintering behavior of different weak layer grain types is relevant. All advances towards both, natural and artificial release modelling require more detailed data on fracture mechanical properties describing weak layer failure.

In general, models for material failure need to describe the deformation before failure, the initial flaw formation and eventually the resistance to fracture (Anderson, 2005). In view of avalanche release modelling, slab elastic modulus and density as well as weak layer fracture energy and strength are suitable to describe failure initiation and crack propagation and their natural variations (Reuter et al., 2015). Yet, all these mechanical properties are not simulated independently in snowcover models, but density parametrizations are used to estimate them. However, simulated vertical density profiles are often smoother than observed in nature (Reuter et al., 2016) and in addition, using density alone is insufficient due to influences of snow microstructure such as its anisotropy or bonding (e.g. Hagenmuller et al., 2014). Along with the measurements of the relevant snow mechanical properties, a description of the microstructure is also needed.

The present work aims at characterizing snow failure in persistent as well as non-persistent weak layers at short times after burial based on cold laboratory experiments. To this end, we loaded small layered snow samples in shear and performed 2-

80 D strain analysis based on image correlation to derive fracture mechanical properties, including strength, modulus and fracture toughness. Snow samples were produced in the lab and contained a weak layer of surface hoar, facets or decomposing fragmented particles sitting on a strong snow base and covered by a slab. Tests and measurements were repeated in the same weak layer series to study the temporal evolution of fracture mechanical properties between 30 minutes and 8 hours after burial. In addition, we characterize our samples with the help of snow micro-penetration, microcomputed tomography and near infrared photography.

\section{Methods}

\subsection{Mechanical experiments}

In a cold laboratory we prepared 26 layered snow samples consisting of a three layered structure. A well sintered layer, a weak mid-layer with a slab sitting on top. We tested the layered samples in shear, recorded fracture for analysis with digital image correlation (DIC) and measured snow desnity with micro-penetrometry and micro-computed tomography.

\subsubsection{Procedure}


The Cryosphere Discuss., https://doi.org/10.5194/tc-2018-268

Manuscript under review for journal The Cryosphere

Discussion started: 4 January 2019

(c) Author(s) 2019. CC BY 4.0 License.

We used artificially produced snow that resembles typical snow types found in nature. At the surface of a snow filled box representing a well-sintered base, we prepared a weak layer. Then we sifted snow on top - simulating a slab - which had four shear frames inserted (Figure 1). After letting the layers sinter for at least $30 \mathrm{~min}$, up to 6 SMP measurements were taken around the first shear frame. Then, snow was removed from around the shear frame perimeter to a depth below the frame of about $2 \mathrm{~cm}$. One vertical sidewall was sprayed with a stochastic speckle pattern for DIC analysis of the spatial strain due to the mechanical loading. A measurement series consists of four such mechanical tests. These are associated with up to 6 SMP measurements and 3 micro-computed tomographs $(\mu \mathrm{CT})$ obtained from the region between the planar area outlined by the shear frames. After the first series of SMP measurements around the first shear frame, the shear test was performed. Then, the first $\mu \mathrm{CT}$ sample was taken and scanned before we proceeded with the SMP measurements around the next shear frame and so on (Figure 1).

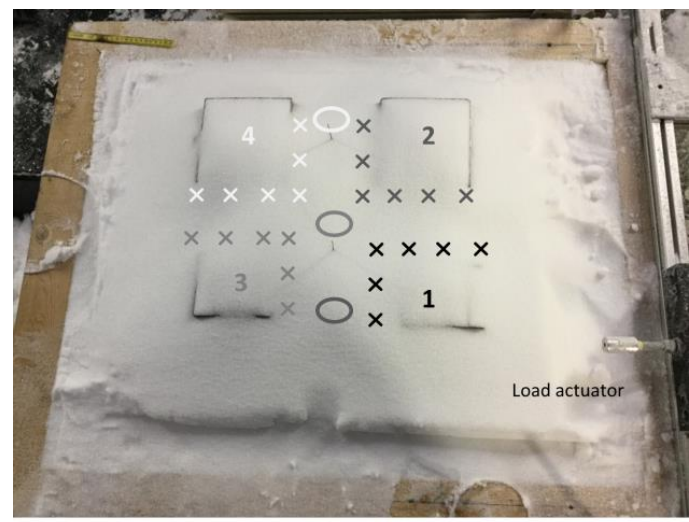

Figure 1: Measurement setup including shear frames (numbers), SMP (crosses) and $\mu$ CT measurements (ellipses). Gray levels from dark to bright indicate time lag from first measurement.

\subsubsection{Weak layer preparation}

The weak layer was either a surface hoar (SH) layer that was grown on a well sintered base or it was deposited by sifting disaggregated particles onto that base (Figure 2).
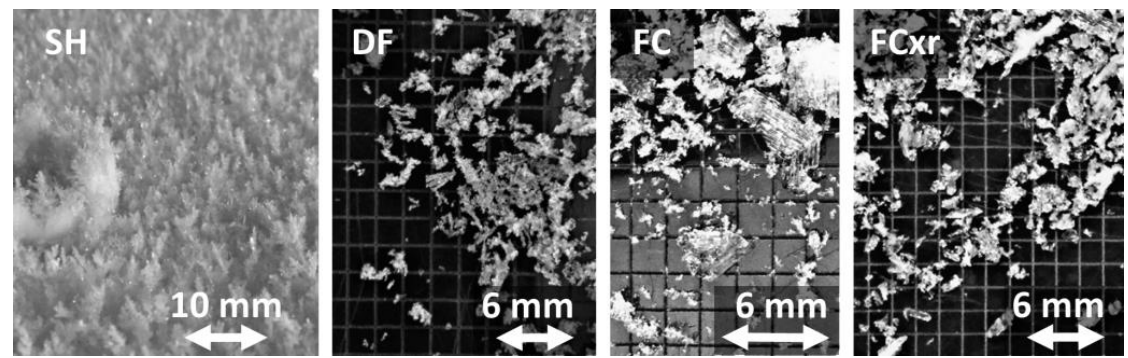

Figure 2: Pictures of weak layer grain types including intact surface hoar near sample holder (SH) and disaggregated grains of decomposing fragmented (DF), faceted (FC) and rounding faceted particles (FCxr).

Growing surface hoar took between 4 and 8 hours and was usually done the day before in similar manner as Stanton et al. (2012). To do so, the snow surface was exposed to a $-50{ }^{\circ} \mathrm{C}$ ceiling temperature in conjunction with a cold chamber air temperature of $-14^{\circ} \mathrm{C}$, yielding a snow surface temperature of about $-16^{\circ} \mathrm{C}$. Water vapor was supplied from a heated water tank to provide low velocity flow across the snow surface $\left(1 \mathrm{~m} \mathrm{~s}^{-1}\right)$. At the water vapor outlet the air temperature was around $-4^{\circ} \mathrm{C}$. Disaggregated particles that we sifted onto the base to form a weak layer were either decomposing fragmented dendritic particles (DF) artificially produced in a snow maker or faceted crystals. The faceted crystals (FC) were grown from vapor onto the cold chamber ceiling that we swept. Faceted crystals (FC) were swept prior to the 
The Cryosphere Discuss., https://doi.org/10.5194/tc-2018-268

Manuscript under review for journal The Cryosphere

Discussion started: 4 January 2019

(c) Author(s) 2019. CC BY 4.0 License.

experiment. Rounding facted crystals (FCxr) formed when these crystals were kept for several days in a box at $-14^{\circ} \mathrm{C}$. Characteristics are provided in Table 1. Grain types and sizes were classified according to Fierz et al. (2009). Density and specific surface area were determined from micro-computed tomography. Layer height was measured in near-infrared images.

Table 1: Characteristics of the snow layers involved in the study: traditional grain type and size, mean density, median specific surface area (SSA), average height of shear strain concentration zone.

\begin{tabular}{l|l|r|r|r|r} 
Layer & Grain type & $\begin{array}{l}\text { Grain size } \\
(\mathrm{mm})\end{array}$ & $\begin{array}{l}\text { Density } \\
\left(\mathrm{kg} \mathrm{m}^{-3}\right)\end{array}$ & $\begin{array}{l}\text { SSA } \\
\left(\mathrm{m}^{2} \mathrm{~kg}^{-1}\right)\end{array}$ & $\begin{array}{l}\text { Height } \\
(\mathrm{mm})\end{array}$ \\
\hline Slab & RG, FC & .5 & 330 & - & $25-38$ \\
Weak layer & SH & 3 & 180 & 45 & 7 \\
Weak layer & DF & 2.5 & 220 & 30 & 9 \\
Weak layer & FC & 6 & 215 & 13 & 8 \\
Weak layer & FCxr & 2 & 220 & 35 & 7 \\
Base & RG, FC & .5 & 380 & - & $>40$
\end{tabular}

\subsubsection{Slab layer preparation}

125 The slab layer was added by sifting disaggregated snow particles initially produced in the snow maker on top of the weak layer. We used either small rounded or slightly faceted grains (Table 1) which were usually stored more than 2 weeks at a constant temperature of $-14^{\circ} \mathrm{C}$. We placed the shear frames after we had sifted a couple of millimeters to keep the distance between the weak layer and the frames small - while maintaining the integrity of the weak layer when placing the frames.

\subsubsection{Data acquisition}

130 During the mechanical test synchronized measurements of force, displacement and high speed images were recorded at a sampling rate of $500 \mathrm{~s}^{-1}$. A load actuator moved a rod to push the shear frame horizontally to apply a force at constant displacement rate of between 0.2 and $0.5 \mathrm{~mm} \mathrm{~s}^{-1}$. A load cell measured the force which increased until failure to about between 10 and $30 \mathrm{~N}$ depending on the shear frame size, which had an area of either 0.025 or $0.0105 \mathrm{~m}^{2}$. The size effect of different shear frames on shear stress was accounted for by the scaling factors for different shear frames sizes reported by

135 Föhn (1987).

\subsection{Snow micro-penetrometry}

The snow micro-penetrometer (SMP) measures vertical signals of penetration resistance. Hence, in our signals the slab as well as the weak layers are represented. Following the approach for signal interpretation suggested by Löwe and van Herwijnen (2012) snow microstructural parameters, namely, structural element length, $L$, deflection at rupture, $\delta$, and

140 rupture force, $f$, are obtained. These three microstructural properties have been used in the past to derive mechanical properties including snow density, elastic modulus, specific fracture energy or weak layer strength (e.g. Reuter et al., 2018).

Snow density was obtained with a parametrization suggested by Proksch et al. (2015), but using coefficients derived that are specific to our SMP device. This calibration was based on the $\mu \mathrm{CT}$ samples and allowed deriving density from all SMP signals measured in the vicinity of the shear frames.

145 Density variations between the samples were assessed by averaging the SMP signals associated with each shear test sample.

\subsection{Micro-computed tomography}

Micro-computed tomography ( $\mu \mathrm{CT}$ ) is an imaging technique to recover the 3D structure of samples (Coléou et al., 2001). We took X-ray scans at resolutions between 10 and $16 \mu \mathrm{m}$ with a Sky-Scan X-ray scanner located in a cold chamber. Between the series of mechanical tests (Figure 1) $\mu \mathrm{CT}$ samples were taken. However, not all $\mu \mathrm{CT}$ samples could be moved to the X-ray scanner without disturbing the weak layer, thus reducing the number of usable samples. From intact samples the snow density and specific surface area was derived for the three stratigraphic layers. 
The Cryosphere Discuss., https://doi.org/10.5194/tc-2018-268

Manuscript under review for journal The Cryosphere

Discussion started: 4 January 2019

(c) Author(s) 2019. CC BY 4.0 License.

\subsection{Digital image correlation}

A digital image correlation (DIC) technique provided a means to derive strain during deformation until failure. Syncing the force readings to the camera with time facilitated identifying the moment of failure in the image records. In the relevant frames the software GOM Correlate was used to determine unique contrast patterns to calculate strain. We obtained values of shear strain, $\tau$, in the coordinate system depicted on the right in Figure 2 by averaging across the region concentrating the shear strain. We compared this area with near-infrared images (Figure 2 - background) of the samples' sidewall clearly depicting the weak layer below the slab. Overlapping the DIC strain result and the near-infrared images we could see where the deformation and the failure occurred.

Values of shear strain obtained for every image frame allowed us to calculate the shear strain rate and the shear modulus of the weak layer. A fit of shear strain and time provided the shear strain rate. Similarly, we obtained the shear modulus $\mu$ from a regression of the shear stress, $\tau$, based on the force signal at the load cell and the DIC-derived shear strain.

\subsection{Brittle Failure}

As failure we consider the abrupt decrease during a few milliseconds in the shear stress with respect to the global shear strain measured on the sample. Hence, we refer to failure as the catastrophic fracture of the before connected ice structure. The frame at the beginning of this decrease of stress was chosen for calculations. To quantify whether the failure was

170 brittle, we used the concept of strain energy intensity. In a shear experiment the strain energy intensity $u$ represents the amount of energy per unit volume due to shear strain $\gamma$ :

$u=\int \tau d \gamma$.

Evaluating the integral to the linear elastic limit $\gamma_{\text {lim }}$ yields the linear elastic part of the strain energy intensity $u_{\mathrm{LE}}$. To calculate the plastic portion of the strain energy intensity $u_{\mathrm{P}}$ the integral needs to be evaluated between the shear strain at

175 the linear elastic limit $\gamma_{\text {lim }}$ and the shear strain at failure $\gamma_{\mathrm{f}}$ :

$u_{\mathrm{P}}=\int_{\gamma_{\text {lim }}}^{\gamma_{\mathrm{f}}} \tau d \gamma$

The larger the amount of non-recoverbale deformation, i.e. the higher the plastic portion of the strain energy intensity $u_{\mathrm{P}}$, the stronger is the deviation from brittle failure. In the case of linear elastic - perfectly plastic behavior, i.e. constant stress but increasing strain beyond the linear elastic limit $\gamma_{\text {lim }}$, the plastic portion of the strain energy intensity $u_{\mathrm{P}}$ represents the amount of dissipated energy.

\subsection{Shear fracture toughness}

We estimated the weak layer fracture toughness for our mode II experiment series from the critical energy release rate. The energy release rate, $G$, is determined from the change of strain energy, $U$, during extension of a crack in the weak layer of 185 length $a$ :

$G=-\frac{1}{B} \frac{\partial U}{\partial a}$

where $B$ is the thickness of the specimen. At the critical crack length, the energy release rate yields the critical energy release rate, $G_{\mathrm{c}}$. In our case, for simple shear, the linear elastic strain energy can be obtained from (Higdon et al., 1985):

$U=\frac{\tau^{2}(L-a) B H}{2 \mu}=u_{\mathrm{LE}}(L-a) B H$,

190 where $L$ is the length of the intact part of the weak layer, $H$ the thickness of the weak layer and $u_{\mathrm{LE}}$ the linear elastic strain energy intensity. We obtain an expression for the shear fracture toughness, $\boldsymbol{K}_{\mathbf{I I c}}=\sqrt{\boldsymbol{G}_{\boldsymbol{c}} \boldsymbol{\mu}}$, by combining equations (3) and (4) to $\boldsymbol{K}_{\text {IIc }}=\sqrt{\boldsymbol{u}_{\mathrm{LE}} \boldsymbol{H \mu}}$. In many materials crack tip plasticity adds to the material's resistance to fracture (p. 61, Anderson, 2005) and can be characterized with the fracture process zone, which has been estimated for snow (McClung, 1979). Also in our experiments the strain energy intensity leading to failure includes a plastic portion $\boldsymbol{u}_{\mathbf{p}}$. Thus we extend the strain energy intensity to: 
Hence, for our specific geometry and loading situation the shear fracture toughness can be estimated independently of the crack length - a property that our experiments do not directly measure.

\subsection{Measures of significance and uncertainty}

We report the Pearson correlation coefficient $r_{\mathrm{p}}$ and the $p$-value to describe the significance $(p<0.05)$ of a linear relationship between two quantities. Since we are dealing with small data sets (e.g. our time series with $\mathrm{N}=3$ or 4 ) we omitted a significance test, and only concluded on the direction of the trend if the correlation coefficient was $\left|r_{\mathrm{p}}\right|>0.3$ and the same trend was observed in all time series of the same weak layer type. For linear regressions we report the coefficient of determination $R^{2}$ and the $p$-value of the slope.

The measurement uncertainty of the shear modulus was derived from the $95 \%$ confidence intervals of the regression slope of the shear stress with respect to the shear strain. Propagating the independent uncertainties of the weak layer thickness, the strain energy intensity and the shear modulus yielded an estimate for the uncertainty of the fracture toughness. The uncertainty of the weak layer thickness measurement was assumed $1 \mathrm{~mm}$. Modifying the integration interval to determine the work per unit volume in the stress-strain diagram provided a measure of the uncertainty for the work per unit volume. In fact, we changed the upper integration boundary by one frame to obtain a different value of the work per unit volume which would correspond to failure happening one frame before it actually happened.

\section{Results}

First, we show one experiment in more detail to illustrate the methodology before we summarize the experimental results with a focus on fracture mechanical properties. Then we explore the temporal changes we observed in different layers.

\subsection{Elastic-plastic deformation}

Figure 2 shows the sidewall of sample 2 that we tested on 1 July 2018. The near-infrared picture in the background highlights the weak stratigraphy due to a layer of surface hoar that is embedded between stiffer layers sitting above and below. This stratigraphy led to a concentration of high shear strain during the stress build up. Just before failure the shear strain in the weak layer reached about 0.0018 . Overlapping the DIC strain analysis and the near-infrared picture confirmed that the deformation and eventually the failure occurred in the weak layer. To estimate the concentration of the shear strain in the weak layer we calculated a ratio comparing the shear strains in the slab and the weak layer. Figure 4 shows the increase of shear stress and strain until failure for the same sample. The ratio of shear strains indicates that the shear strain in the slab reached, at most, $6 \%$ of the shear strain observed in the weak layer. Hence, before failure the shear strain in the weak layer was at least 16 times higher than in the slab layer above.

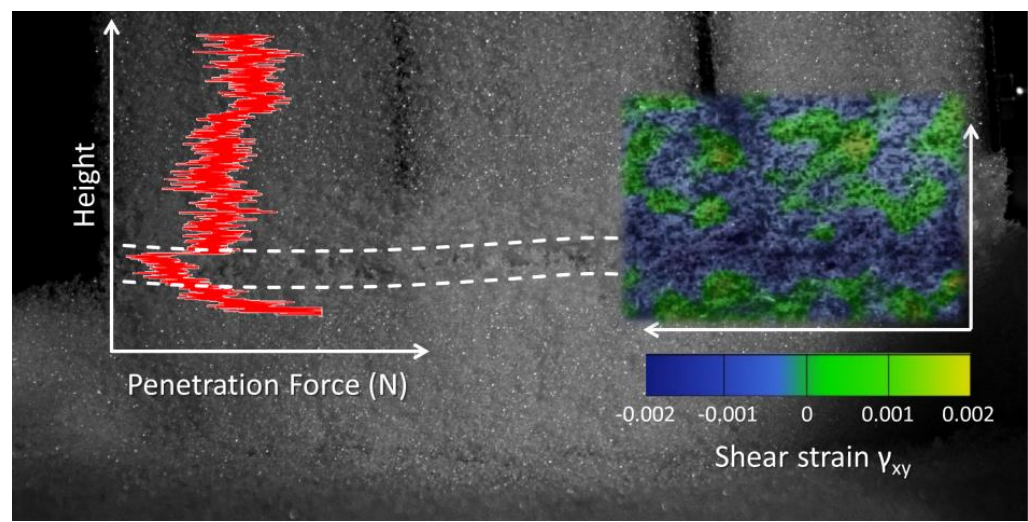

Figure 3: Near-infred picture of shear experiment overlain with SMP signal (red) and DIC shear strain analysis (colorscheme). Two dashed lines embrace the weak layer. 
The Cryosphere Discuss., https://doi.org/10.5194/tc-2018-268

Manuscript under review for journal The Cryosphere

Discussion started: 4 January 2019

(c) Author(s) 2019. CC BY 4.0 License.

230 A clear brittle failure is marked by an abrupt drop of stress. In Figure 4, however, from shear strain values above the linear elastic limit $\gamma_{\text {lim }}=0.0016$ the stress no longer increases, indicating plastic deformation. This behavior can be classified as essentially linear elatic - perfectly plastic. Using this, we can estimate the amount of non-recoverable energy by the plastic portion of the strain energy intensity. For better comparison between measurements we scaled by the total strain energy intensity, i.e. including elastic and plastic deformation. In the example shown in Figure 4 this ratio was $22 \%$.

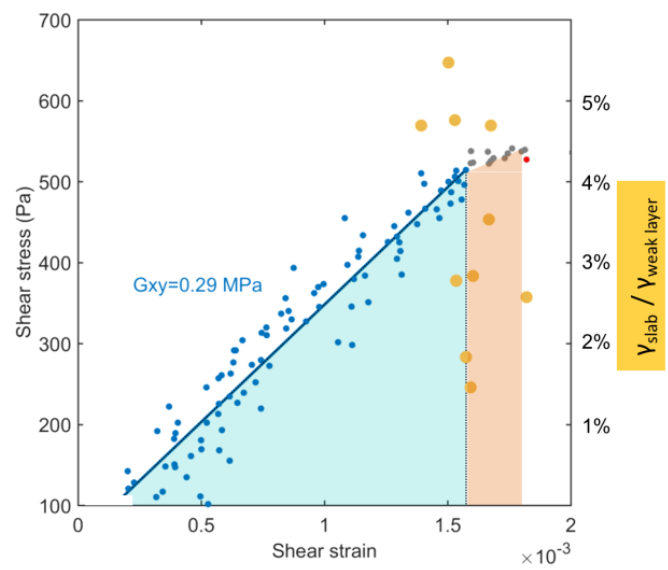

Figure 4: Shear stress and shear strain in the weak layer are shown by blue and grey dots for sample 2 on 1 July 2018; blue dots represent values within the linear elastic limit, grey dots are beyond that. A red dot marks failure. The value of the shear modulus was determined by a linear regression (blue line) and the blue area under the regression shows the strain energy intensity of the linear elatic part of the deformation; for a linear elastic - perfectly plastic behavior the orange area represents the non-recoverable part of the deformation. The work per unit volume until failure is represented by the blue and the orange area. The shear strain in the slab relative to the weak layer is shown by yellow dots for selected frames before failure.

\subsection{Synthesis of results for different weak layers}

Table 2 compiles the results we obtained for the three different weak layers (DF, SH, and FC(xr)). In all experiments we observed a concentration of the shear strain in the weak layer ultimately leading to failure after plastic deformation. The amount of non-recoverable energy was $20-30 \%$ on average. Shear strength values were on the order of $1 \mathrm{kPa}$, shear moduli were on the order of $1 \mathrm{MPa}$ and strain rates around $10^{-3} \mathrm{~s}^{-1}$. Decomposing or fragmented particles had the lowest average values of shear strength, shear modulus and shear fracture toughness, but generally speaking, variations between different weak layer types were not very pronounced.

Table 2: Summary of the results for different weak layer types. Average values for every weak layer type and the standard deviation are provided.

\begin{tabular}{r|c|c|c|c|c|c|c}
$\begin{array}{c}\text { Weak } \\
\text { layer } \\
\text { type }\end{array}$ & $\mathrm{N}$ & $\begin{array}{c}\text { Shear } \\
\text { Strength } \\
(\mathrm{kPa})\end{array}$ & $\begin{array}{c}\text { Shear } \\
\text { Modulus } \\
(\mathrm{MPa})\end{array}$ & $\begin{array}{c}\text { Fracture } \\
\text { Toughness } \\
\left(\mathrm{Pa} \mathrm{m}^{1 / 2}\right)\end{array}$ & $\begin{array}{c}\text { Strain rate } \\
\left(10^{-3} \mathrm{~s}^{-1}\right)\end{array}$ & $\begin{array}{c}\text { Strain in } \\
\text { weak layer } \\
(\%)\end{array}$ & $\begin{array}{c}\text { Non-recoverable } \\
\text { strain energy } \\
\text { intensity (\%) }\end{array}$ \\
\hline $\mathrm{SH}$ & 11 & $1.4 \pm 0.4$ & $1.0 \pm 0.4$ & $135 \pm 32$ & $2.3 \pm 1.6$ & $85 \pm 14$ & $28 \pm 13$ \\
$\mathrm{DF}$ & 7 & $1.0 \pm 0.2$ & $0.9 \pm 0.4$ & $106 \pm 26$ & $2.8 \pm 2.1$ & $85 \pm 15$ & $23 \pm 12$ \\
$\mathrm{FC}(\mathrm{xr})$ & 8 & $1.4 \pm 0.2$ & $2.1 \pm 1.1$ & $128 \pm 38$ & $0.9 \pm 0.4$ & $80 \pm 19$ & $19 \pm 15$
\end{tabular}

\subsection{Shear fracture toughness and shear modulus}

Our experiments yielded values of the fracture toughness, using equation 5 , to be between 55 and $205 \mathrm{~Pa} \mathrm{~m}^{1 / 2}$ with an average of $124 \mathrm{~Pa} \mathrm{~m}^{1 / 2}$ and were at the lower end or below previously reported values (Figure 5). Interestingly, decomposing fragmented particles had the lowest average value (Table 2) even lower than surface hoar. Values of the shear 
The Cryosphere Discuss., https://doi.org/10.5194/tc-2018-268

Manuscript under review for journal The Cryosphere

Discussion started: 4 January 2019

(c) Author(s) 2019. CC BY 4.0 License.

modulus varied between 0.3 and 3.3 MPa with an average of 1.2 MPa. Rounding facets had significantly higher values of the shear modulus.

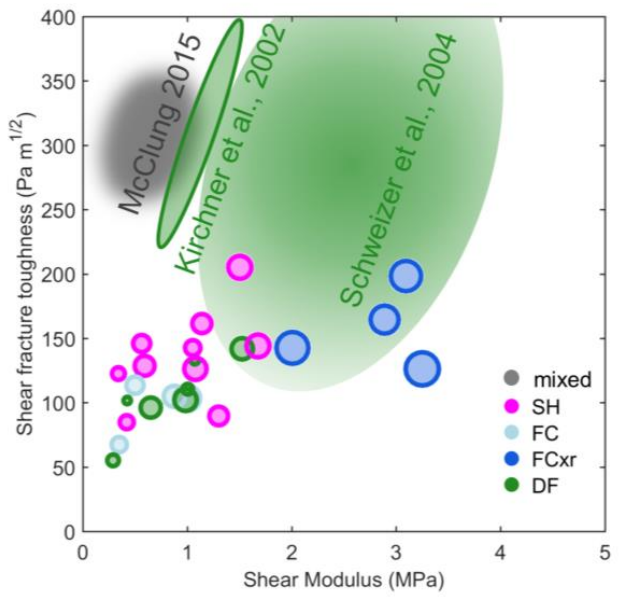

Figure 5: Shear fracture toughness and shear modulus for different grain types (colors) from previous studies and the presented experiments including lag times after burial (circle size). In previous studies values of shear modulus $\mu$ were either reported or we estimated the values based on $\mu=E / 2 /(1+v)$ with Poisson's ratio $v=0.2$ and elatic modulus $E$ from reported snow density (Scapozza, 2004).

In Figure 5 a softer and more brittle material would sit in the lower left corner, whereas stiffer and tougher materials would be found in the upper right corner. Our values of shear fracture toughness and modulus are specifically for weak layers, whereas previous studies rarely included active weak layers. Hence, it is no surprise that most of our results concentrate in the lower left. But it is interesting how different weak layer grain types group. Decomposing fragmented particles are found close to surface hoar.

With increasing lag time after burial (circle size in Figure 5) the shear fracture toughness and the shear modulus increased. This result is true regardless of weak layer grain type. Differences between specific weak layers are shown in the next section.

\subsection{Temporal variations}

We tested one specific weak layer in a series of up to four tests performed at different lag times after adding the slab as illustrated in Figure 1. This allows studying the evolution of mechanical properties of a certain weak layer during the first hours after burial. 

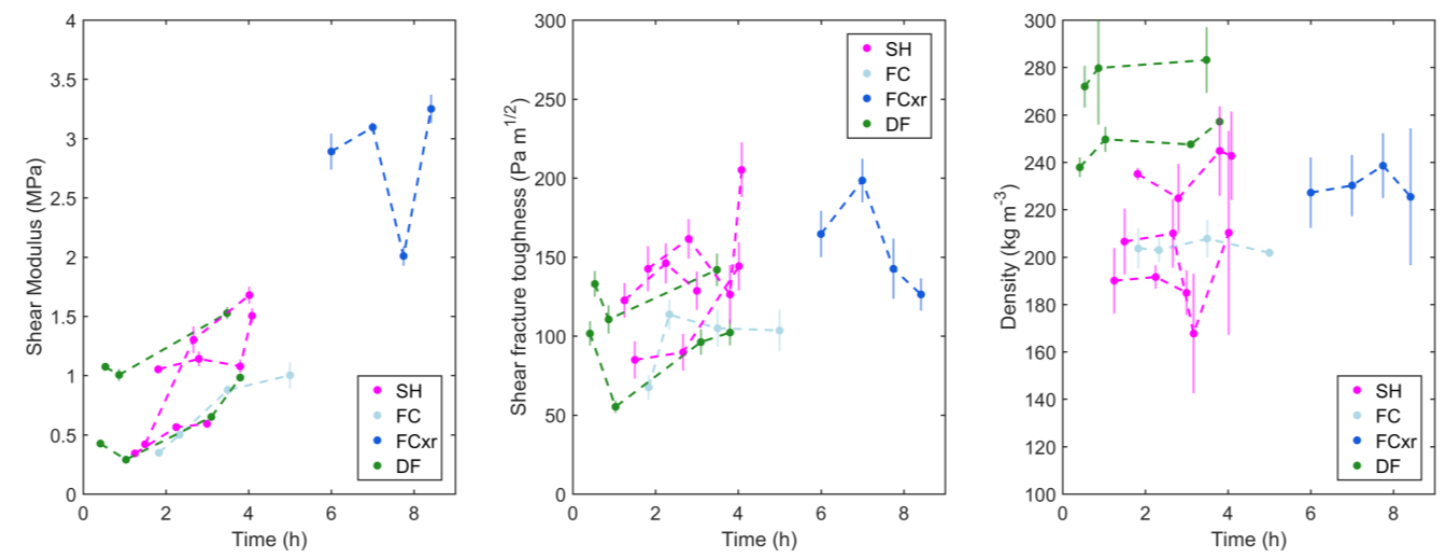

Figure 6: Temporal variation of (a) shear modulus, (b) shear fracture toughness and (c) density, including variations for different weak layer grain types (colors) and experiment series (connected by dashed lines). Bars show estimates of measurement uncertainty.

The results for shear modulus and fracture toughness after different lag times are shown in Figure $6 \mathrm{a}$ and $\mathrm{b}$, including error estimates. The shear modulus increased in the series of surface hoar $\left(r_{\mathrm{p}}=0.94, r_{\mathrm{p}}=0.65, r_{\mathrm{p}}=0.96\right)$ and decomposing fragmented particles $\left(r_{\mathrm{p}}=0.90, r_{\mathrm{p}}=0.98\right)$. Changes in faceted crystals, i.e. FC $\left(r_{\mathrm{p}}=0.96\right)$ and FCxr $\left(r_{\mathrm{p}}=-0.03\right)$ did not allow a conclusion. Increases of shear fracture toughness were less pronounced but had consistent sign in the series of surface hoar $\left(r_{\mathrm{p}}=0.33, r_{\mathrm{p}}=0.41, r_{\mathrm{p}}=0.92\right)$ and decomposing fragmented particles $\left(r_{\mathrm{p}}=0.40, r_{\mathrm{p}}=0.64\right)$. Again, faceted crystals results were inconclusive $\left(r_{\mathrm{p}}=0.47, r_{\mathrm{p}}=-0.65\right)$. The error estimates reflect the uncertainty of measuring, but do only partly account for the experimental uncertainty, which would require repeated measurements. The variations presented in Table 1 contain both, the measurement and the experimental error, but also temporal effects - providing a more conservative error estimate.

Changes of shear strength were inconclusive in surface hoar $\left(r_{\mathrm{p}}=-0.98, r_{\mathrm{p}}=-0.56, r_{\mathrm{p}}=0.70\right)$ and faceted crystals $\left(r_{\mathrm{p}}=0.76\right.$, $\left.r_{\mathrm{p}}=-0.37\right)$. Decomposing fragmented, however, increased in shear strength $\left(r_{\mathrm{p}}=0.73, r_{\mathrm{p}}=0.98\right)$ (not shown) with a strengthening rate of about $0.09 \mathrm{kPa} \mathrm{h}^{-1}\left(R^{2}=0.32, p=0.01\right)$.

Weak layer densification as a process explaining these changes is unlikely since the changes of weak layer density we measured were within the measurement uncertainty and variability. In fact, Figure $6 \mathrm{c}$ shows that the weak layer density did not change significantly during the time of the experiments (two negative, two positive, three non-conclusive relations with $r_{\mathrm{p}}<0.2$ ). Moreover, the density variations we measured are in the same range as the measurement errors and the inter sample variability determinded from repeated SMP measurements (one standard variation of at least four measurements).

Structural changes associated with the lag times may have influenced other mechanical properties. Changes of strain concentration in the weak layer with lag time were inconclusive, i.e. in our experiment series of a certain weak layer type no pattern existed towards increasing or decreasing strain concentration (4 positive and 3 negative correlations). The plastic portion of the strain energy intensity did not show a pattern of change in our experiment series, i.e. it neither decreased nor increased for the series of a certain weak layer type ( 3 positive and 4 negative correlations). Hence, we can assume that time did not influence how much of the deformation was contained in the weak layer or how large the portion of the plastic deformation was. Consequently, we can pool the data to look at the failure behavior.

\subsection{Rate dependent failure behavior}

305 Our measurements show that samples with lower shear modulus and lower shear fracture toughness deformed at higher strain rates. Strain rates varied between $4 \cdot 10^{-4}$ and $10^{-2} \mathrm{~s}^{-1}$. Correlations of the strain rate with shear modulus $\left(r_{\mathrm{p}}=-0.57\right.$; $p=0.003$, Figure 7) and with shear fracture toughness $\left(r_{\mathrm{p}}=-0.40 ; p=0.05\right.$, not shown) were both significant. The plastic portion of the strain energy intensity as a measure of the deviation from perfectly brittle failure (for $0 \%$ ) was unrelated to the strain rate $\left(r_{\mathrm{p}}=0.11 ; p=0.62\right)$. 
The Cryosphere Discuss., https://doi.org/10.5194/tc-2018-268

Manuscript under review for journal The Cryosphere

Discussion started: 4 January 2019

(c) Author(s) 2019. CC BY 4.0 License.

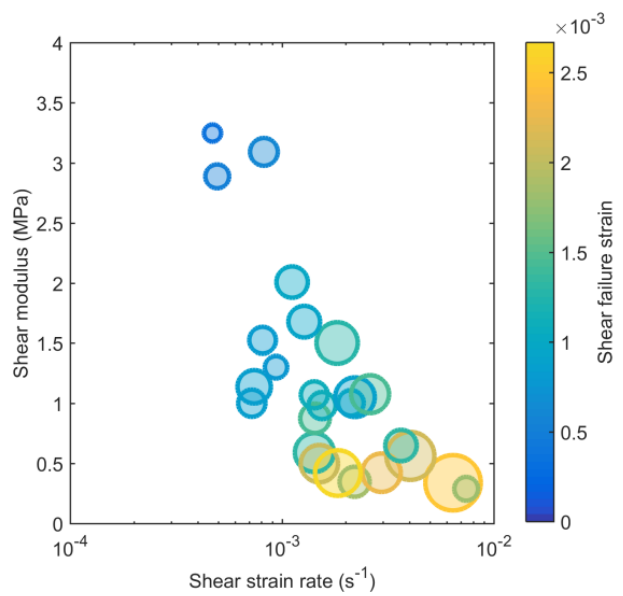

Figure 7: Shear strain rate and shear modulus for all data $(\mathrm{N}=\mathbf{2 6})$. Colors denote shear failure strain. Circle size indicates total strain energy intensity until failure.

The strain rate dependency of the observed failure behavior is also linked to shear failure strain $\left(r_{\mathrm{p}}=0.63 ; p=0.001\right)$ and total strain energy intensity $\left(r_{\mathrm{p}}=0.47 ; p=0.02\right)$. Apparently, weak layers with a lower modulus failed at higher strains and after more energy per unit volume was expended.

Relations of the strain rate with the shear strength $\left(r_{\mathrm{p}}=-0.32 ; p=0.12\right)$ or the plastic portion of the strain energy intensity $\left(r_{\mathrm{p}}=0.11 ; p=0.61\right)$ are not significant. Hence, we can summarize the strain rate dependency of the observed failure behavior in the scheme in Figure 8.

320

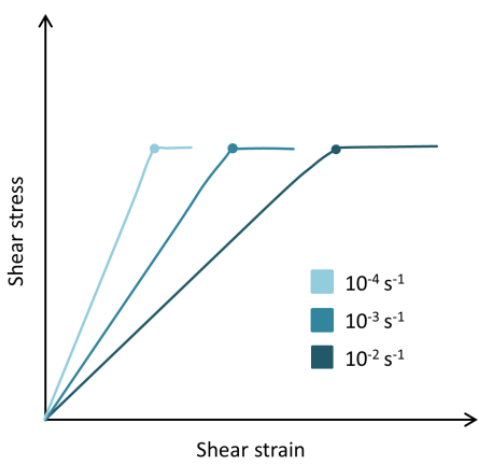

Figure 8: Schematic of the strain rate dependent linear elastic - perfectly plastic failure behavior as observed in our shear experiments.

\subsection{Calibration of SMP-derived modulus}

325 To derive a microscale elastic modulus, $E_{\mathrm{SMP}}$, from the SMP-derived microstructural parameters, the rupture force, $f$, deflection at rupture, $\delta$, and structural element length, $L$, are employed. Previous research (Reuter et al., 2019) has suggested the following expression: 
The Cryosphere Discuss., https://doi.org/10.5194/tc-2018-268

Manuscript under review for journal The Cryosphere

Discussion started: 4 January 2019

(c) Author(s) 2019. CC BY 4.0 License.

We found a coefficient $c=59$ (for $E_{\mathrm{SMP}}$ in MPa, $f$ in N, $\delta$ and $L$ in $\mathrm{mm}$ ) to well represent the shear modulus, $\mu$, we had measured in experiments with decomposing fragmented or surface hoar grains yielding $R^{2}=0.5 ; r_{\mathrm{p}}=0.71 ; p=0.002$ for these selected grain types (Figure 9). This model, however, does not reflect the different shear moduli we found in faceted grains.

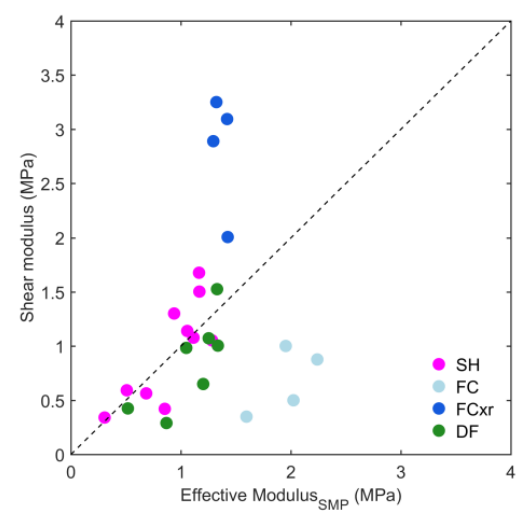

Figure 9: Experimental results of shear modulus are compared to a calibration of the SMP-derived effective modulus. 1:1 line is dashed.

\section{Discussion}

Different methods have been developed in the past decade to derive mechanical properties of snow including (a) mechanical testing (e.g. Reiweger et al., 2010;Walters et al., 2010), (b) modelling of reconstructed micro-computed tomography (e.g. Wautier et al., 2015;Köchle and Schneebeli, 2014) or (c) acoustic emission measurements (Capelli et al., 2016).

340 Here we derived fracture mechanical properties of three typical weak snow layers using a high speed imaging setup and performing unconfined shear failure experiments similar to Walters and Adams (2014). Weak layers consisted of decomposing and fragmented particles, surface hoar and faceted crystals allowing comparisons.

\subsection{Strain concentrations}

In overlapping high speed video frames and NIR images of the failure we observed consistent failure in the weak layer confirming earlier observations of failure in layered snow samples (e.g. Joshi et al., 2006). Moreover, applying a DIC algorithm to these videos revealed that the weak layer had usually concentrated more than $80 \%$ of the shear strain, which is compatible with values of Reiweger and Schweizer (2010). Hence, to measure material properties or the strain rate relevant for weak layer failure, data from the failure zone rather than the entire sample need to be considered.

\subsection{Strain softening}

350 Based on early shear experiments snow was characterized as a quasi-brittle strain softening material (McClung, 1977). In our experiments we observed a small region of plastic deformation, but the strain softeneing was not apparent. Essentially, we observed linear elastic - perfectly plastic behavior, in which case the plastic region would define the dissipative energy.

Important results of earlier studies included the strain rate dependency on the failure behavior and in particular, the transition between ductile and brittle behavior (e.g. Narita, 1983). Measuring and modelling acoustic emissions during weak layer tests at slow and high loading rates (Capelli et al., 2018b) revealed the active processes during both regimes. Slow loading rate experiments were in the ductile range and allowed for failed bonds to heal, yielding larger values of failure strain and strength. On the contrary, the high loading rate experiments had brittle failure after small total strains of $10^{-3}$. Hence during slow loading damage and healing were balanced. Our samples deformed at shear strain rates between $10^{-4}$ and $10^{-2} \mathrm{~s}^{-1}$ and failed at shear strains of around $10^{-3}$ including about 20-30\% of non-recoverable strain energy per unit 
The Cryosphere Discuss., https://doi.org/10.5194/tc-2018-268

Manuscript under review for journal The Cryosphere

Discussion started: 4 January 2019

(c) Author(s) 2019. CC BY 4.0 License.

360 volume. So, despite "high" strain rates and small strains our samples showed some plastic deformation - irrespective of grain type.

Strain softening is considered a general characteristic of snow deformation and was observed in shear in homogeneous samples from strain rates below $10^{-4} \mathrm{~s}^{-1}$ (Fukuzawa and Narita, 1993) or $10^{-3} \mathrm{~s}^{-1}$ (Schweizer, 1998). In surface hoar samples, however, Reiweger and Schweizer (2010) observed hardly any strain softening in their force controlled tests and Walters and Adams (2014) reported brittle failure in displacement controlled tests of radiation recrystallized snow. Both reported global strain rates on the order of $10^{-4} \mathrm{~s}^{-1}$, although the relevant strain rate may have been higher as the strain concentrated in the weak layer. As Reiweger et al. (2010) had observed strain softening in homogeneous samples for the same strain rates, Reiweger and Schweizer (2010) suggested that strain softening in surface hoar is very small and hence, may have contributed little to the deformation they measured. Our surface hoar was on average half their surface hoar's size ( $3 \mathrm{~mm}$ vs. $6 \mathrm{~mm}$ ) and we measured smaller failure strains (0.002 vs. 0.004 to 0.07). Similarly, we did not observe strain softening but essentially perfect plastic deformation after yielding.

\subsection{Fracture mechanical properties}

The shear strength has been measured early on (e.g. de Quervain, 1950) and shear frame measurements of typical weak layers usually yield values between several hundreds up to $2000 \mathrm{~Pa}$ (Jamieson and Johnston, 2001). Reiweger et al. (2015)

375 compiled data from mixed mode load controlled tests of different weak layers fitting a Mohr-Coulomb law with an average cohesion of $0.17 \mathrm{kPa}$. Displacement controlled tests reached shear strengths between 0.4 and $2 \mathrm{kPa}$ for radiation recrystallized weak layers (Walters and Adams, 2014). We measured values around $1 \mathrm{kPa}$ that also seems compatible with Reiweger et al. (2015) as their densities were significantly lower.

380 In general, the snow strength depends on the strain rate (e.g. Narita, 1983). In mixed mode loading experiments of surface hoar (Reiweger and Schweizer, 2010) and facets or depth hoar (Reiweger and Schweizer, 2013) snow strength decreased with inceasing strain rate. In our data, a trend of decreasing shear strength with increasing strain rate was weak and not significant. We hypothesize that this effect may become less pronounced towards higher strain rates which is also what Schweizer's (1998) data suggest.

Fracture toughness so far was only measured on homogeneous snow samples. Laboratory tests found values of shear fracture toughness as low as $100 \mathrm{~Pa} \mathrm{~m}^{1 / 2}$ (Kirchner et al., 2002; Schweizer et al., 2004). We derived the shear fracture toughness for our unnotched samples from estimates of the total strain energy intensity before failure. The obtained values of 55-205 $\mathrm{Pa} \mathrm{m}^{1 / 2}$ correspond to the lower end of the previous laboratory results, which seems reasonable given that we tested weak layers exclusively. The calculation of the fracture toughness was based on the linear elastic and the plastic portion of the strain energy obtained for the weak layer. We neglected the strain energy stored in the slab, as the strain in the slab was about one order of magnitude lower and the ratio between slab and weak layer SMP-derived elastic moduli ranged between 2 and 4 for our samples depending on weak layer type.

Measurements of the shear modulus of snow are rare, in particular for typical weak layer grain types. In dynamic torsional shear experiments of samples of small rounded or faceted grains including partly decomposed and fragmented particles Schweizer and Camponovo (2002) had measured an average shear modulus of $0.7 \mathrm{MPa}$. This value is consistent, even if

395 slightly lower than our results with average values of $0.9 \mathrm{MPa}$ and $2.1 \mathrm{MPa}$ for DF and FC grains, respectively. This seems acceptable given that our snow grains were larger on average $(2-6 \mathrm{~mm})$ than their tested snow grains $(0.4-0.5 \mathrm{~mm})$. Walters and Adams (2014) measured stiffness in faceted layers and obtained values comparable to our values for FC samples. Moreover, they could relate decreasing values of the shear modulus to radiation recrystallization.

With micro-tomography image based modelling Köchle and Schneebeli (2014) obtained values of the isotropic elastic

400 modulus for 17 weak layers between 2 and $100 \mathrm{MPa}$, approximately corresponding to shear moduli between 1 and $60 \mathrm{MPa}$. Wautier et al. (2015) modeled a shear modulus of $80 \mathrm{MPa}$ for decomposing fragmented and of $270 \mathrm{MPa}$ for faceted crystals.

Values of the elastic moduli from 3D modelling are about one order of magnitude higher than values from mechanical testing including our data. Köchle and Schneebeli (2014) attributed those differences to lower strain rates in mechanical tests leading to non-recoverable deformation and consequently, possible lower estimates of the modulus in case of insufficient measurement resolution. Yet, our measurements resolve the initial deformation at strains on the order of $10^{-4}$ and strain rates were as high as $10^{-2} \mathrm{~s}^{-1}$ for some tests. Moreover, the amount of non-recoverable strain energy intensity we measured was independent of the weak layer strain rate. In our data some plastic deformation always occurred. Hence, nonrecoverable deformation is an unlikely explanation for the differences in the shear modulus. We believe that the differences are not only related to the methodolgy, but may also be related to differences between the snow samples used. Direct comparisons between measurements and modelling are needed to understand these differences, as has been done for SMP- 
The Cryosphere Discuss., https://doi.org/10.5194/tc-2018-268

Manuscript under review for journal The Cryosphere

Discussion started: 4 January 2019

(c) Author(s) 2019. CC BY 4.0 License.

and micro-tomography derived parameters (Reuter et al., 2019). To compare with the above mentioned studies, additional information such as snow strength could tell how fragile the layers were.

Whether or not the initial deformation measured in mechanical tests only contains reversible deformation is currently not clear. It remains to be shown, if the initial part of deformation is indeed recoverable.

\subsection{Fracture behavior in different weak layers}

To fully describe a material's fracture behavior a combination of several mechanical properties including elastic modulus, toughness, failure strain or strength are required. Assuming linear elasticity, deformation can be described by the elastic modulus and resistance or energy to fracture can be described by the toughness. Hence, a typical fragile material will have

420 both, low modulus and low toughness. From our experiments both properties could be obtained and we can compare decomposing fragmented particles, which form relevant weak layers during storms, to persistent grain types (Figure 5). Our results of shear modulus and shear fracture toughness suggest that in the first hours after burial decomposing fragmented particles are just as prone to fail as surface hoar. Although the results seem intuitive from a field perspective, it has rarely been measured due to the short time window these grains are weak before they transisiton into less fragile forms. The data of specific fracture energy presented by van Herwijnen et al. (2016) contained 6 cases of precipitation particles that had the lowest values among all grain types which agrees with our finding that storm snow can be fragile in the first hours.

To unify data from mixed mode loading experiments of surface hoar, facets and depth hoar layers Reiweger et al. (2015) presented a new Mohr-Coulomb-Cap criterion describing shear, tensile and normal strength. They found that higher

430 loading rates were required to achieve brittle failure in stiffer layers compared to softer layers. In general, high strain rates result from either higher loading rates or lower moduli. In our experiments variations of loading rate were small due to stable displacement rates around $3.7 \mathrm{~mm} \mathrm{~s}^{-1}$, allowing the strain rate and elastic modulus to be related. We observed that weak layers with a lower modulus such as the DF samples failed at higher strain rates, whereas weak layers with a higher modulus such as the FCxr samples failed at lower strain rates. Hence, to create a high strain rate in load controlled

435 experiments a high loading rate is required, in particular if the samples have a low modulus such as weak layers.

\subsection{Temporal changes in different weak layers}

Generally speaking, differences in fracture mechanical properties between grain types were rather small compared to temporal variations. Increases of shear modulus and fracture toughness with increasing lag time were significant, in particular for surface hoar and decomposing fragmented particles (Figure 6).

440 During the first hours after deposition snow strength is also expected to increase if conditions favor sintering over faceting (Podolskiy et al., 2014). However, in our data only the decomposing fragmented particles gained shear strength with time at a rate of $0.09 \mathrm{kPa} \mathrm{h}^{-1}$. This rate is in the range of 0.07 to $0.3 \mathrm{kPa} \mathrm{h}^{-1}$ reported for weak layers of surface and depth hoar in the field by Birkeland et al. (2006), but is lower than the average rate of $0.7 \mathrm{kPa} \mathrm{h}^{-1}$ reported for homogeneous snow samples of old rounded and decomposing particles by Podolskiy et al. (2014). They measured changes in shear strength at different times after a horizontal cut had separated the sample. Their higher strengthening rates may be related to faster sintering between their small disaggregated grains relative to the large grains in our samples or the field data.

We assume that the temporal changes we measured are likely related to sintering during so called "equi-temperature" metamorphism. Indeed, this type of metamorphism is the only relevant process that occurred during our experiment series since our experimental design does not provide for relevant temperature gradients across the samples.

\subsection{Calibrating measurements and models}

We assessed whether a formulation to derive an effective modulus from the SMP can be used to estimate the shear modulus. The parametrization worked fairly well for surface hoar and decomposing fragmented particles, but not for faceted (FC) and rounding faceted (FCxr) grains. Assuming that the process behind the increase of the modulus in surface hoar and decomposing fragmented particles was sintering, the SMP may reflect the sintering related increase in penetration resistance (van Herwijnen and Miller, 2013). Presently, the formulation for the SMP-derived modulus can be used with a calibration factor of 59 to estimate the shear modulus for surface hoar and decomposing fragmented particles.

To model snow properties, and weak layer properties in particular, microstructure needs to be considered. Our measurement series showed that neither shear strength nor shear modulus were related to weak layer density (both $r_{\mathrm{p}}<0.3$, $p>0.2$ ), but likely evolved due to sintering. Hence, parametrizations of mechanical properties should possibly also be based on specific surface area, age or overburden stress such as shown for snow strength by Conlan and Jamieson (2015). Such 
The Cryosphere Discuss., https://doi.org/10.5194/tc-2018-268

Manuscript under review for journal The Cryosphere

Discussion started: 4 January 2019

(c) Author(s) 2019. CC BY 4.0 License.

parametrizations could be obtained by combining micro-computed tomography and mechanical testing data. Unfortunately, due to alignment issues not all of our micro-tomography data are amenable to do that and we cannot provide time series of specific surface area, for instance.

\section{Conclusions}

We performed shear experiments on small snow samples containing a weak layer of surface hoar, decomposing fragmented, or faceted crystals at shear strain rates between $10^{-4}$ and $10^{-2} \mathrm{~s}^{-1}$. In all samples, the weak layers concentrated the strain and failed at shear strains of around $10^{-3}$ including about $20-30 \%$ of non-recoverable strain energy per unit volume.

470 Irrespective of weak layer grain type some plastic deformation before failure occurred despite high strain rates. This result became apparent with DIC of frames from the failure zone, but was obscured in global displacement measurements. Weak layers with lower elastic moduli failed at higher failure strains and higher strain rates, while the shear strength remained rather unchanged. At higher strain rates in our measurements the rate dependency of strength was less pronounced.

475 Our results of shear modulus and shear fracture toughness suggest that in the first hours after burial decomposing fragmented particles are just as fragile as surface hoar. This sounds intuitive, but time series reflecting such changes are rare. Conditions for sufficient strengthening, when decomposing fragmented particles are no longer prone to fail, could be studied in the future.

Our measurements of shear strength, elastic shear modulus and fracture toughness compare well with existing data. Values of shear modulus from microstructural based modelling are, however, often higher by one order of magnitude. Our strain measurements resolve the initial deformation and hence, we believe measure the elastic shear modulus.

Variations of shear strength and shear modulus could be explained with lag times between sample preparation and shear testing. In our case of generally equi-temperature conditions, we conclude that sintering caused increases in shear modulus and fracture toughness in surface hoar and decomposing fragmented particles. Shear strength increased in decomposing fragmented particles at a rate of $0.09 \mathrm{kPa} \mathrm{h}^{-1}$, which is compatible with previous research.

Calibrating a SMP-based model for the effective modulus yielded good agreement for the shear modulus of surface hoar and decomposing fragmeneted particles.

Given the changes in fracture mechanical properties we have observed, including microstructural properties reflecting the metamorphic changes seems key for deriving parametrizations of mechanical properties for snow cover modelling. Moreover, we believe that mechanical testing including high resolution deformation measurements combined with microstructural modelling can shed light on the failure mechanisms in different weak layer structures. This combination of methods could also reveal the reasons for differences between mechanical properties determined with both approaches.

\section{Acknowledgments and Data}

495 We thank Ladean McKittrick for helpful support and discussions, and Chris Donahue and Trenton Aiello for their help during the lab experiments. B.R. has been founded by the Swiss National Science Foundation (P2EZP2_168896). Data will be available on request.

\section{References}

Anderson, T. L.: Fracture Mechanics: Fundamentals and Applications, 3rd ed., CRC Press, Boca Raton FL, U.S.A., 640 pp., 2005.

Bair, E. H., Simenhois, R., Birkeland, K., and Dozier, J.: A field study on failure of storm snow slab avalanches, Cold Regions Science and Technology, 79-80, 20-28, 10.1016/j.coldregions.2012.02.007, 2012.

Birkeland, K. W., Kronholm, K., Logan, S., and Schweizer, J.: Field measurements of sintering after fracture of snowpack weak layers, Geophysical Research Letters, 33, L03501, doi:03510.01029/02005GL025104, 2006. 
The Cryosphere Discuss., https://doi.org/10.5194/tc-2018-268

Manuscript under review for journal The Cryosphere

Discussion started: 4 January 2019

(c) Author(s) 2019. CC BY 4.0 License.

505 Capelli, A., Kapil, J. C., Reiweger, I., Or, D., and Schweizer, J.: Speed and attenuation of acoustic waves in snow: laboratory experiments and modelling with Biot's theory, Cold Regions Science and Technology, 125, 1-11, 10.1016/j.coldregions.2016.01.004, 2016.

Capelli, A., Reiweger, I., Lehmann, P., and Schweizer, J.: Fiber bundle model with time-dependent healing mechanisms to simulate progressive failure of snow, Physical Review E, 98, 023002, 10.1103/PhysRevE.98.023002, 2018a.

510 Capelli, A., Reiweger, I., and Schweizer, J.: Acoustic emissions signatures prior to snow failure, Journal of Glaciology, 64, 543-554, 10.1017/jog.2018.43, 2018b.

Coléou, C., Lesaffre, B., Brzoska, J.-B., Ludwig, W., and Boller, E.: Three-dimensional snow images by X-ray microtomography., Annals of Glaciology, 32, 75-81, 2001.

Conlan, M. J. W., and Jamieson, B.: Formation and strengthening of layers of dry faceted crystals above artificial melt-

515 freeze crusts from overburden stress in a controlled environment, Canadian Geotechnical Journal, in press, 10.1139/cgj2015-0045, 2015.

de Quervain, M. R.: Die Festigkeitseigenschaften der Schneedecke und ihre Messung, Geofisica Pura e Applicata, 18, 4-15, 1950.

Fierz, C., Armstrong, R. L., Durand , Y., Etchevers, P., Greene, E., McClung, D. M., Nishimura, K., Satyawali, P. K., and

520 Sokratov, S. A.: The International Classification for Seasonal Snow on the Ground, HP-VII Technical Documents in Hydrology, IACS Contribution No 1, UNESCO-IHP, Paris, France, 90 pp., 2009.

Föhn, P. M. B.: The stability index and various triggering mechanisms, Symposium at Davos 1986 - Avalanche Formation, Movement and Effects, IAHS Publ., 162, 1987, 195-214, 1987.

Fukuzawa, T., and Narita, H.: An experimental study on the mechanical behavior of a depth hoar under shear stress, Proceedings ISSW 1992. International Snow Science Workshop, Breckenridge, Colorado, U.S.A., 4-8 October 1992, 1993, 171-175,

Gaume, J., and Reuter, B.: Assessing snow instability in skier-triggered snow slab avalanches by combining failure initiation and crack propagation, Cold Regions Science and Technology, 144, 6-15, 10.1016/j.coldregions.2017.05.011, 2017.

530 Gaume, J., van Herwijnen, A., Chambon, G., Wever, N., and Schweizer, J.: Snow fracture in relation to slab avalanche release: critical state for the onset of crack propagation, The Cryosphere, 11, 217-228, 10.5194/tc-11-217-2017, 2017.

Gaume, J., Gast, T., Teran, J., van Herwijnen, A., and Jiang, C.: Dynamic anticrack propagation in snow, Nature Communications, 9, 3047, 10.1038/s41467-018-05181-w, 2018.

Haegeli, P., and Schweizer, J.: Recent developments in applied snow and avalanche research, Cold Regions Science and 535 Technology, 120, 153-156, 10.1016/j.coldregions.2015.09.008, 2015.

Hagenmuller, P., Calonne, N., Chambon, G., Flin, F., Geindreau, C., and Naaim, M.: Characterization of the snow microstructural bonding system through the minimum cut density, Cold Regions Science and Technology, 108, 72-79, http://dx.doi.org/10.1016/j.coldregions.2014.09.002, 2014.

540 Sons, New York, 1985.

Jamieson, J. B., and Johnston, C. D.: Evaluation of the shear frame test for weak snowpack layers, Annals of Glaciology, 32, 59-68, 10.3189/172756401781819472, 2001.

Joshi, S. K., Mahajan, P., and Upadhyay, A.: Study of layered snow under shear and tension, Proceedings ISSW 2006. International Snow Science Workshop, Telluride CO, U.S.A., 1-6 October 2006, 2006.

545 Kaempfer, T. U., and Schneebeli, M.: Observation of isothermal metamorphism of new snow and interpretation as a sintering process, Journal of Geophysical Research-Atmospheres, 112, D24101, 10.1029/2007jd009047, 2007.

Kirchner, H. O. K., Michot, G., and Schweizer, J.: Fracture toughness of snow in shear and tension, Scripta Materialia, 46, 425-429, 2002.

Köchle, B., and Schneebeli, M.: Three-dimensional microstructure and numerical calculation of elastic properties of alpine snow with a focus on weak layers, Journal of Glaciology, 60, 705-713, 10.3189/2014JoG13J220, 2014. 
The Cryosphere Discuss., https://doi.org/10.5194/tc-2018-268

Manuscript under review for journal The Cryosphere

Discussion started: 4 January 2019

(c) Author(s) 2019. CC BY 4.0 License.

McClung, D. M.: Direct simple shear tests on snow and their relation to slab avalanche formation, Journal of Glaciology, 19, 101-109, 1977.

McClung, D. M.: Shear fracture precipitated by strain softening as a mechanism of dry slab avalanche release, Journal of Geophysical Research, 84, 3519-3526, 10.1029/JB084iB07p03519, 1979.

555 Mock, C. J., and Birkeland, K. W.: Snow avalanche climatology of the western United States mountain ranges, Bulletin of the American Meteorological Society, 81, 2367-2392, 2000.

Narita, H.: An experimental study on tensile fracture of snow, Contributions from the Institute of Low Temperature Science, A32, 1-37, 1983.

Podolskiy, E. A., Barbero, M., Barpi, F., Chambon, G., Borri-Brunetto, M., Pallara, O., Frigo, B., Chiaia, B., and Naaim,

560 M.: Healing of snow surface-to-surface contacts by isothermal sintering, The Cryosphere, 8, 1651-1659, 10.5194/tc-81651-2014, 2014.

Reiweger, I., and Schweizer, J.: Failure of a layer of buried surface hoar, Geophysical Research Letters, 37, L24501, 10.1029/2010GL045433, 2010.

Reiweger, I., Schweizer, J., Ernst, R., and Dual, J.: Load-controlled shear apparatus for snow, Cold Regions Science and Technology, 62, 119-125, 10.1016/j.coldregions.2010.04.002, 2010.

Reiweger, I., and Schweizer, J.: Weak layer fracture: facets and depth hoar, The Cryosphere, 7, 1447-1453, doi:10.5194/tc7-1447-2013, 2013.

Reiweger, I., Gaume, J., and Schweizer, J.: A new mixed-mode failure criterion for weak snowpack layers, Geophysical Research Letters, 42, 1427-1432, 10.1002/2014GL062780, 2015.

570 Reuter, B., van Herwijnen, A., Veitinger, J., and Schweizer, J.: Relating simple drivers to snow instability, Cold Regions Science and Technology, 120, 168-178, 10.1016/j.coldregions.2015.06.016, 2015.

Reuter, B., Richter, B., and Schweizer, J.: Snow instability patterns at the scale of a small basin, Journal of Geophysical Research-Earth Surface, 121, 257-282, 10.1002/2015JF003700, 2016.

Reuter, B., and Schweizer, J.: Describing snow instability by failure initiation, crack propagation, and slab tensile support, Geophysical Research Letters, 45, 7019-7027, 10.1029/2018GL078069, 2018.

Reuter, B., Proksch, M., Löwe, H., van Herwijnen, A., and Schweizer, J.: Comparing measurements of snow mechanical properties relevant for slab avalanche release, Journal of Glaciology, 65, in press, 10.1017/jog.2018.93, 2019.

Scapozza, C.: Entwicklung eines dichte- und temperaturabhängigen Stoffgesetzes zur Beschreibung des visko-elastischen Verhaltens von Schnee, Ph.D., Institut für Geotechnik, ETH Zurich, Zurich, Switzerland, 250 pp., 2004.

580 Schweizer, J., and Lütschg, M.: Characteristics of human-triggered avalanches, Cold Regions Science and Technology, 33 , 147-162, 2001.

Schweizer, J., and Camponovo, C.: The temperature dependence of the effective elastic shear modulus of snow, Cold Regions Science and Technology, 35, 55-64, 2002.

Schweizer, J., Michot, G., and Kirchner, H. O. K.: On the fracture toughness of snow, Annals of Glaciology, 38, 1-8, 2004.

585 Schweizer, J., Reuter, B., van Herwijnen, A., and Gaume, J.: Avalanche release 101, Proceedings ISSW 2016. International Snow Science Workshop, Breckenridge CO, U.S.A., 3-7 October 2016, 2016, 1-11,

Stanton, B., Miller, D., and Adams, E.: Analysis of Surface Hoar Growth Under Simulated Meteorological Conditions, Proceedings, 2012 International Snow Science Workshop, Anchorage, Alaska, 2012.

van Herwijnen, A., and Miller, D. A.: Experimental and numerical investigation of the sintering rate of snow, Journal of Glaciology, 59, 269-274, 10.3189/2013JoG12J094, 2013.

van Herwijnen, A., Gaume, J., Bair, E. H., Reuter, B., Birkeland, K. W., and Schweizer, J.: Estimating the effective elastic modulus and specific fracture energy of snowpack layers from field experiments, Journal of Glaciology, 62, 997-1007, 10.1017/jog.2016.90, 2016. 
The Cryosphere Discuss., https://doi.org/10.5194/tc-2018-268

Manuscript under review for journal The Cryosphere

Discussion started: 4 January 2019

(c) Author(s) 2019. CC BY 4.0 License.

(c) (i)

Walters, D. J., Adams, E. E., Staron, P. J., and McKittrick, L. R.: Shear deformation of radiation recrystallized near surface facets, Proceedings ISSW 2010. International Snow Science Workshop, Lake Tahoe CA, U.S.A., 17-22 October 2010, 2010, 80-87,

Walters, D. J., and Adams, E. E.: Quantifying anisotropy from experimental testing of radiation recrystallized snow layers, Cold Regions Science and Technology, 97, 72-80, 10.1016/j.coldregions.2013.09.014, 2014.

600

Wautier, A., Geindreau, C., and Flin, F.: Linking snow microstructure to its macroscopic elastic stiffness tensor: A numerical homogenization method and its application to 3-D images from X-ray tomography, Geophysical Research Letters, 42, 2015GL065227, 10.1002/2015GL065227, 2015. 